\title{
NEW CROSSOVERS USING A COMBINED FILM TECHNIQUE
}

\author{
GÜNTER KIESSLING \\ Siemens AG, Unternehmensbereich Bauelemente, München, BRD
}

(Received April 24, 1978)

\begin{abstract}
This paper was presented at the IEEE Committee for Passive Components and their Materials International
\end{abstract} Conference on Thin and Thick Film Technology, held at Augsburg, 28-30 September 1977.

\section{INTRODUCTION}

The increasing level of integration in film circuit technology, together with the broad-based trend toward miniaturization have led to the necessity for the development of reliable conductor crossovers.

The conditions to be met by such crossovers are

a) Low capacitance with a relatively great crossover height

b) High breakdown voltage

c) Low leakage current

d) Excellent adhesion on glass and ceramic substrates

e) High mechanical stability

f) No pinhole formation

g) Economical production process.

The process evolved in the basic research laboratories of the Siemens AG Components Group is an ideal combination of the advantages of thinfilm and thick-film technologies within the confines of the above conditions.

\section{PRODUCTION}

On flat, carefully cleaned substrates (e.g. Corning Glass Code $7059,99.5 \% \mathrm{Al}_{2} \mathrm{O}_{3}$ ceramic or the like, standard sizes $100 \mathrm{~mm} \times 100 \mathrm{~mm}$ ) coated with an underlayer of tantalum pentoxide, the tantalum thin-film circuit is prepared as far as the first conductor pattern stage. The basic material, developed by us, is aluminium-tantalum containing oxygen $\left(\mathrm{AlTa}+\mathrm{O}_{2}\right){ }^{1,2}$ which is suitably structured by the application of a photoresist and subsequent wet etching. Upon completion of the other work
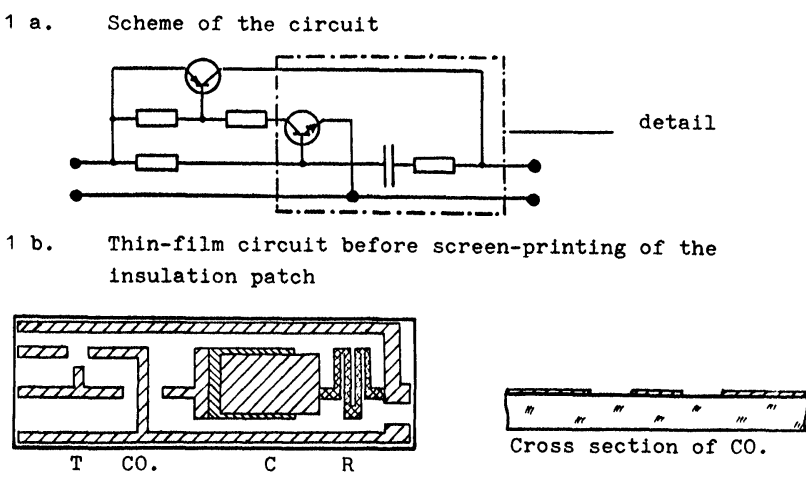

1 c. Circuit with the insulating patch
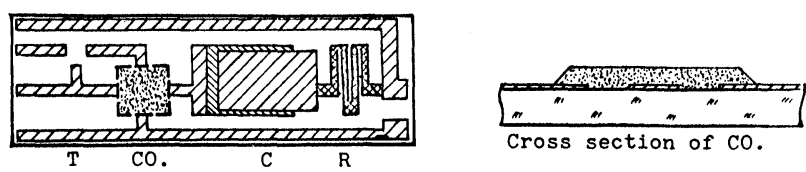

1 d. Finished circuit
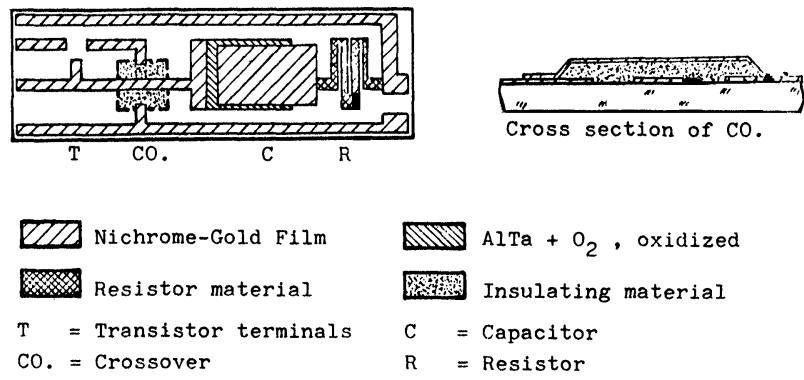

FIGURE 1 Typical RC - circuit with conductor crossover

processes, such as the anodic oxydation of capacitors, resistor trimming, etc., the first film of nichromegold for generation of the basic conductor pattern, the capacitor counter electrodes and the termination lands is vapor-deposited and likewise photographically processed and etched (Figures 1a and 1b). 
The corresponding portions of the circuit are then given an insulating patch for screen-printing (C.O. in Figure 1). For this purpose we use a phenolic resin lacquer (Wiedoprint Lötstopplack LA, red). ${ }^{3}$ In the preliminary experiments, this lacquer, together with epoxy resin lacquers and silicon elastomers, gave the best results. Application via a 320 mesh screen and drying for 30 minutes at $140^{\circ} \mathrm{C}$ (approx. $415^{\circ} \mathrm{K}$ ) produced a film with a thickness of $20 \mu \mathrm{m} \pm 3 \mu \mathrm{m}$ (Figure 1c). In a subsequent vacuum process, a second nichrome-gold layer is vapor-deposited and the desired crossover is formed by the following photoresist and etching process (Figure 1d). As an alternative to the vacuum deposition process, the conductor pattern can be deposited by partial electroplating.

\section{TRIALS}

The crossovers were tried out with two different test patterns:

Test pattern a (Figures 2a and 3): 10 separate circuits, each with 24 conductors with 111 crossovers, were formed on a large substrate $(100 \mathrm{~mm} \mathrm{x}$ $100 \mathrm{~mm}$ ). This gave a total of 1110 crossovers per large substrates. The conductor width varied between $100 \mu \mathrm{m}$ and $500 \mu \mathrm{m}$.

Test pattern $b$ (Figure 2b): 9 separate circuits were formed on one large substrate, each with 14 conductors with 49 crossovers. This gave a total of 441 crossovers per large substrate. The conductor widths were $100 \mu \mathrm{m}$ and $500 \mu \mathrm{m}$.

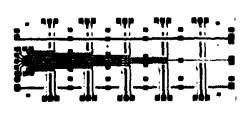

$$
\begin{aligned}
& \text { First } \\
& \text { conductor } \\
& \text { pattern }
\end{aligned}
$$
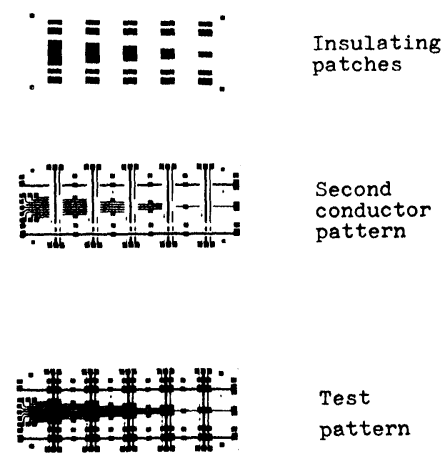

$$
\begin{aligned}
& \text { Test } \\
& \text { pattern }
\end{aligned}
$$
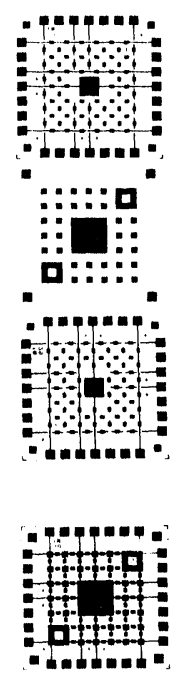

FIGURE 2a Test pattern a

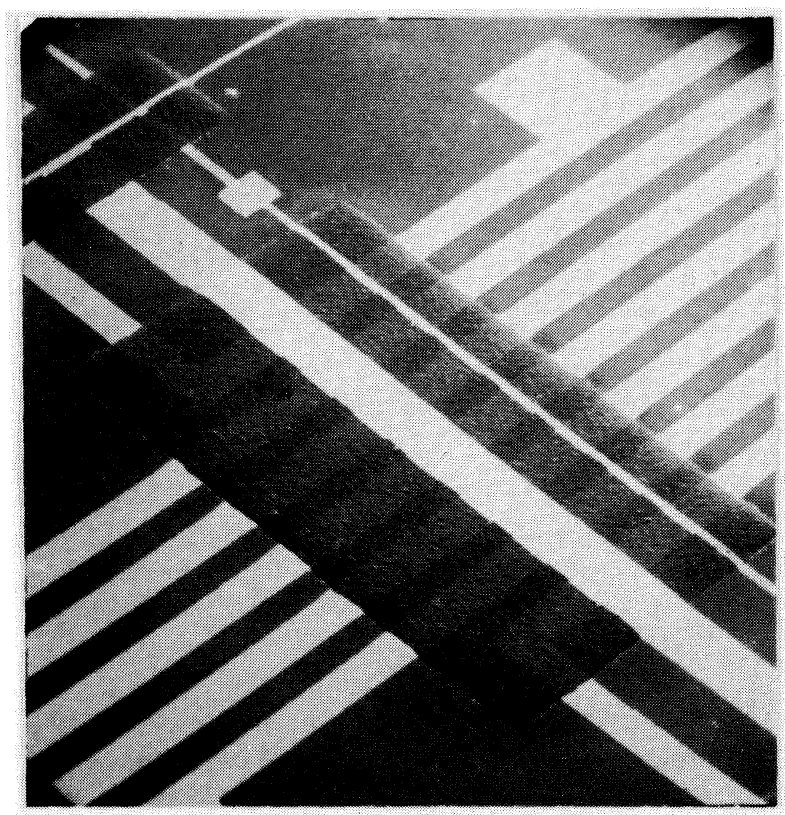

FIGURE 3 SEM photograph of a crossover of test pattern a) (magn. 18x).

\subsection{Mechanical Strength}

3.1.1 Cold shock. The specimen was cooled within 30 seconds to $-196^{\circ} \mathrm{C}(77 \mathrm{~K})$ by immersion in liquid nitrogen and after 10 minutes at this temperature was removed over a period of 30 seconds. Upon return to normal temperature no electrical or, by visual examination, mechanical changes could be ascertained

3.1.2 Heat shock. The same specimen was then subjected to dip soldering conditions, i.e. immersed during 3 to 5 seconds in liquid solder $\left(230^{\circ} \mathrm{C}\right.$, resp. $505 \mathrm{~K}$ ) and then removed. No electrical or mechanical failure occurred here either.

\subsection{Electrical Properties}

3.2.1 Capacitance and loss factor. The capacitance of the crossovers ranged from $0.1 \mathrm{pF}$ for $0.01 \mathrm{~mm}^{2}$ to $1.6 \mathrm{pF}$ for $0.25 \mathrm{~mm}^{2}$. The nonlinearity is due to measuring error and leakage capacitance (Figure 4). The loss factor was determined as $\tan \delta=4 \%$ at $1 \mathrm{kHz}$.

3.2.2 Insulation. The leakage current with an area of $0.25 \mathrm{~mm}^{2}$ and a test voltage of $100 \mathrm{~V} \mathrm{dc}$ was smaller than $0.1 \mathrm{nA}$. The breakdown strength of 


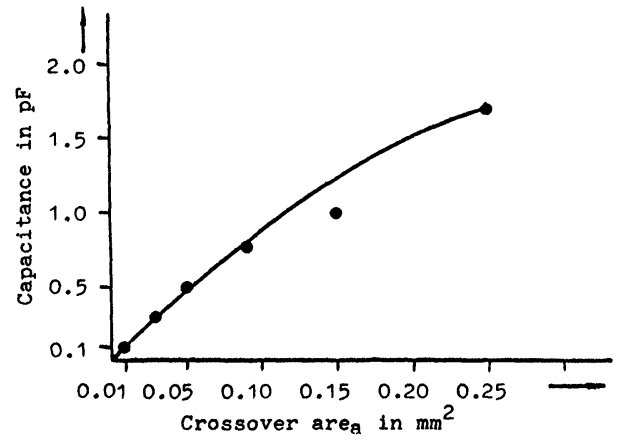

FIGURE 4 Dependence of capacitance from the crossover area.

greater $600 \mathrm{~V}$ dc (equipment maximum $600 \mathrm{~V} \mathrm{dc}$ ) was very good.

\subsubsection{Endurance tests. Endurance testing was} carried out with specimen $b$ (Figure $2 b$ ). The insulation patches varied greatly in area: $1.6 \mathrm{~mm} \mathrm{x}$ $1.6 \mathrm{~mm}, 1.6 \mathrm{~mm} \times 4.6 \mathrm{~mm}$ and $7.6 \mathrm{~mm} \times$ $7.6 \mathrm{~mm}$.

Test a) 490 crossovers were kept at $70^{\circ} \mathrm{C}$ under $50 \mathrm{~V}$ dc.

Test b) 490 crossovers were kept at $40^{\circ} \mathrm{C}$ under $50 \mathrm{~V} \mathrm{dc}$ with relative atmospheric humidity of $92 \%$.

After 7500 hours, no failure was ascertained in case a). In case b) there was 1 failure due to conductor discontinuity and 1 failure due to shortcircuit. These two failures $(0.4 \%)$ were due to manufacturing defects that were not found during initial testing and occurred during the first hours of the test $(<100 \mathrm{~h})$. The leakage current, measured with $250 \mathrm{~V} \mathrm{dc}$, remained in both cases a) and b) at about $0.1 \mathrm{nA}$.
The well-known property of phenolic resin lacquer to absorb moisture should also be taken in account. In order to obtain stable measuring conditions, it was necessary to cool and dry the specimens for about 2 hours at room temperature. For production circuits it will be advisable to apply a moisture-resistant protective coating.

\section{CONCLUSIONS}

The advantages of the described conductor crossovers are

a) satisfaction of all the requirements named in sections.

b) Through this combination of thin-film technology with the cheaper thick-film technology, manufacture becomes considerably more economical than with previously developed and described procedures.

\section{ACKNOWLEDGEMENTS}

I should like to extend my most cordial thanks to Dr. Hoppe for his conscientious supervision of all endurance tests, and to Dr. Schauer for many helpful discussions.

\section{REFERENCES}

1. Research report BMFT - FB T 76-20, Federal Ministry of Research and Technology, June 1976, p. $71 \mathrm{ff}$.

2. H. Kausche, Proc. IEEE 1975: 25th Electron. Comp. Conf., Statler Hilton, Washington DC, May 12-14, 1975.

3. Firma Wiederhold, Bereich Sieb-Druckfarben, 8500 Nürnberg, BRD. 

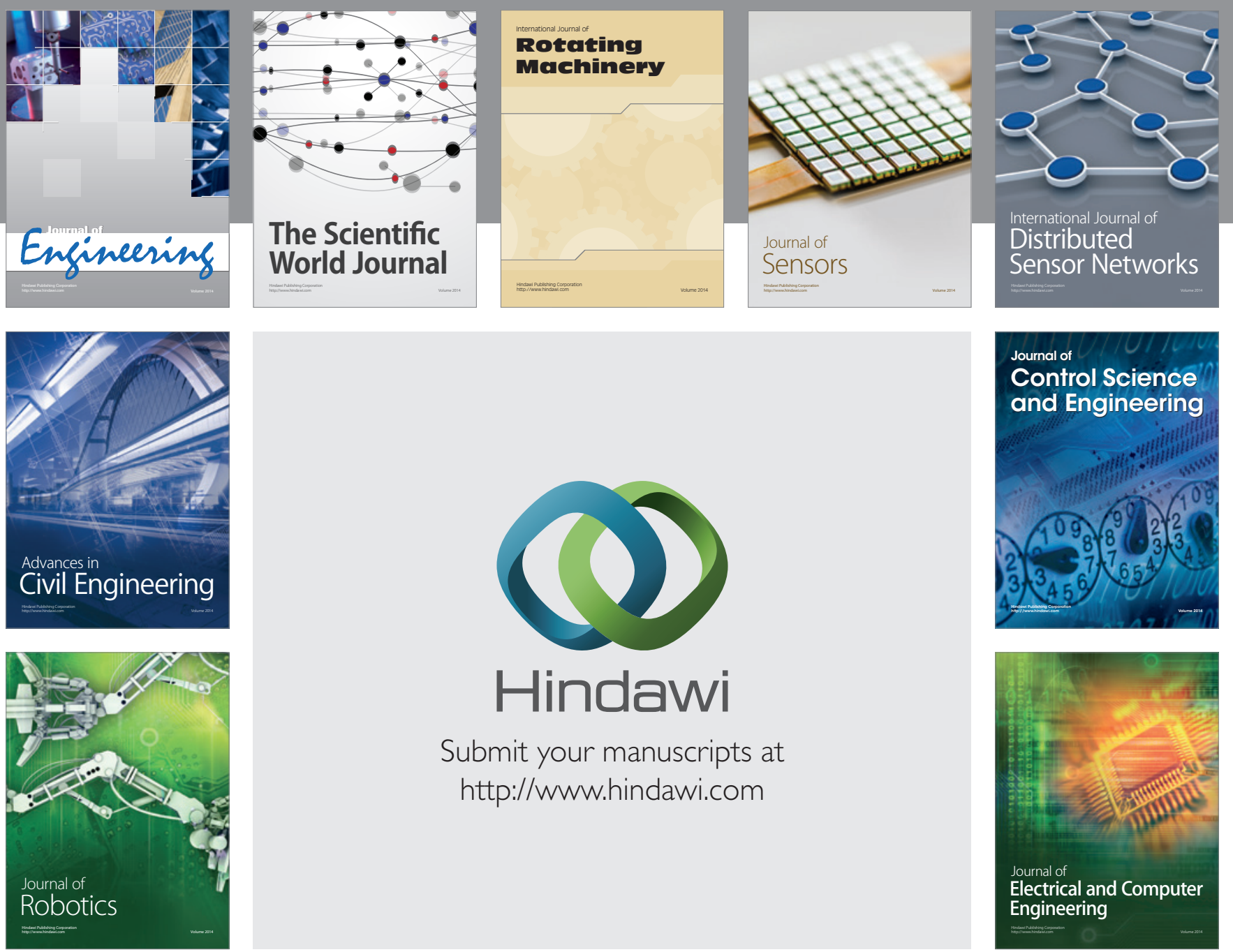

Submit your manuscripts at

http://www.hindawi.com
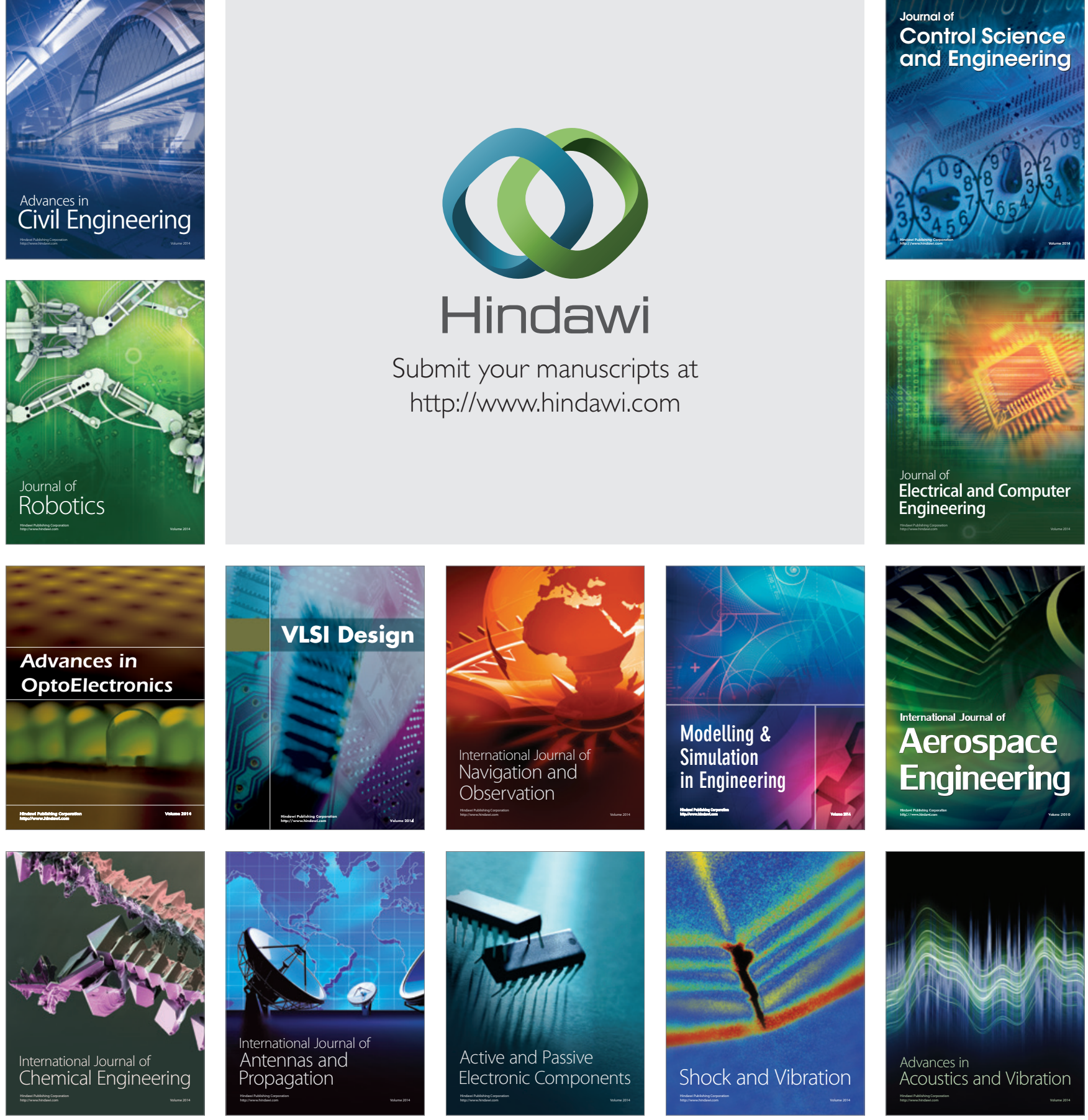